\title{
Analysis of Drivers of Digital Learning in COVID-19 and Post- COVID-19 Scenario Using an ISM Approach
}

\author{
Rohit Agrawal $^{1}$ (D) Vishal Ashok Wankhede ${ }^{2} \cdot$ Rashmi S. Nair $^{3}$
}

Received: 13 August 2020/Accepted: 9 December 2020/Published online: 16 January 2021

(C) The Institution of Engineers (India) 2021

\begin{abstract}
Learning through Internet is becoming necessary for easy understanding of complex problems and knowledge sharing process. A new pedagogy is being demanded in the teaching process which includes digital platforms for better understanding. Moreover, software and hardware have been developed for ease of access to the materials and smooth learning. The COVID-19 pandemic brought various challenges in livelihood of human life. One of these challenges is teaching and learning process. Although teaching and learning include usage of digital media, there exist a need to digitalize the education system. In this regard, this study aimed to analyse the drivers of digital learning in COVID-19 and post-COVID-19 scenario. Sixteen drivers pertaining to digital learning have been considered for analysis. Interpretive structural modelling (ISM) approach has been used to analyse drivers of digital learning and to develop a structural model. The developed structural model was further validated using MICMAC analysis. Results reveal that low Internet cost and government supports are the two prominent drivers of digital learning. The implementation of developed ISM model
\end{abstract}

Rohit Agrawal

mailerrohit@gmail.com

Vishal Ashok Wankhede

vishal.wankhede06@gmail.com

Rashmi S. Nair

reshmianu2010@gmail.com

1 Department of Production Engineering, National Institute of Technology, Tiruchirappalli, Tamil Nadu, India

2 Department of Mechanical Engineering, Pandit Deendayal Petroleum University, Gandhi Nagar, Gujarat, India

3 Department of Computer Applications, National Institute of Technology, Tiruchirappalli, Tamil Nadu, India would create smooth learning environment in COVID-19 and motivates for innovation in post-COVID-19 scenario.

Keywords Digital learning - Education - COVID-19 .

Modelling · Interpretive structural modelling ·

MICMAC analysis

\section{Introduction}

Digital learning is considered to be one of the driver for skill development which likely aids organizations for transformation process [1]. The advent of wireless communication and Internet has led to development of various multimedia networks, namely mobile voice learning and quick messaging [2]. In order to attain the vision of national competitiveness, use of easily accessible technology, i.e. Internet for digital learning would be required which will replace traditional teaching and learning process. Therefore, extensive research had been carried out in mobile learning for achieving high transmission performance and worldwide utilization [2]. In current scenario, more sophisticated and handy devices such as tablets and smartphones are getting matured. Due to the changing environment of teaching and learning process, government and businesses have predominantly invested in the research and development of digital learning modules [2]. A new pedagogy is being demanded in the teaching process which includes digital platforms for better understanding. Moreover, software and hardware have been developed for ease of access to the materials and smooth learning. Various schools have actively presented the use of digital platform for better students learning outcome. Digital technology undoubtedly motivates youth for grabbing further learning opportunities [3]. Devices like laptop along with high- 
speed Internet connection becomes intelligent due to its interoperable and scalable nature. This system breaks the boundaries of time and space for learning process [1]. The COVID-19 pandemic brought various challenges in livelihood of human life. One of these challenges is teaching and learning process. Since March 2020, students in India were involved in the remote learning process due to complete country lockdown. Although the learning pedagogy includes usage of digital media, there exist a need to identify the extensive drivers influencing students learning in this pandemic. In spite of various advantages of digital learning, lack of preparedness affected majority of students learning who were not accessible to these platforms. In this context, the study recognizes digital learning drivers and developed structural model for smooth adoption of Internet-based technology in COVID-19.

\section{Literature Review}

Lewis [4] explored driving factors of digital learning by including both students as well as institutions' perspectives. The study highlights critical success factors such as responsiveness of organization, availability of resources, and efficient management of technology for the sustenance of digital learning. A hypothesis model for the implementation of mobile learning is presented by Liu et al. [5]. A questionnaire-based survey was conducted by considering 230 participants and structural equation modelling was used for analysis of the survey result. The study revealed that perceived long-term usefulness is the most significant driving factor for the successful adoption of mobile learning. Further, Liu et al. [6] presented a literature survey to identify the driving factors and challenges in the adoption of mobile learning. The study presents current situation of mobile learning and summarizes that the main challenge is how to promote mobile learning implementation. The study suggested that the adoption of mobile learning is beneficial for long-term perspectives.

Estelami [7] analysed students experience in complete online education as well as in hybrid education system of online and offline mode. Analysis shows that student's performance is more in hybrid learning as compare to complete online learning. Then, Teo and Wong [8] identified key drivers of digital learning to analyse the satisfaction level of faculties as well as students. Survey was done from 387 participants for the driver analysis of digital learning. Structural equation modelling was used in the study and result shows that tutor quality, ease of use, course satisfaction, and content delivery are essential for the digital learning satisfaction level. Additionally, implications pertaining to digital learning were also discussed. Further in 2016, Medland [9] aimed to analyse impact of curriculum change in the educational institutions of the UK. The study presented the key drivers and barriers of change in the education system. The author also suggested future direction towards assessing learning culture.

Porter et al. [10] presented a framework for the adoption of digital learning in educational institutions. The developed framework mentioned three stages of adoption of digital learning, namely awareness stage, implementation stage, maturity, and growth stage. The study presented key strategies and support measures to be needed to enhance the implementation of digital learning in educational institutions. Survey was conducted with 214 faculties of schools regarding the adoption of digital learning. Further, in 2016, Porter and Graham [11], analysed the degree to which the suggested strategies supports the implementation of digital learning. Results reveal that good infrastructure and technological advancement are the important factors that significantly influence faculties towards the adoption of digital learning.

Sarrab et al. [12] aimed to identify the driving factors for the implementation of mobile learning and to analyse the willingness of students towards the adoption of mobile learning. Technology acceptance model was adopted to analyse the factors that influence mobile learning and its acceptance in the Oman region. Survey was conducted among 806 candidates from 17 Oman based higher educational institutes. Results show that the vital factors are ease of use, enjoyment, and suitability which helps in promoting mobile learning. Further, in 2020, Shao [13] aimed to analyse the satisfaction level of digital learning. Technology acceptance model was used as a framework and questionnaire-based survey was conducted by considering 340 questions. Collected data were analysed through quadratic regression analysis with the help of SPSS software and result revealed that ease of use, usefulness, and behavioural intention are important factors which shows a positive impact on the perceived satisfaction level of digital learning.

\section{Literature Summary}

A systematic literature review has been conducted to analyse the trend of digital learning. From the review, it is found that many authors have done a survey on faculties and students to identify their satisfaction level in adopting digital learning. Some authors have identified several drivers for the adoption of digital learning, such as tutor quality, ease of use, course satisfaction, good infrastructure, technological advancement, and content delivery. But specific studies pertaining to prioritization of drivers is not available in the literature. Many studies are available in countries like the USA, UK, and UAE, but specific studies 
pertaining to India are not being reported in the literature. From the literature review, two research questions have been developed. They are:

Q1: What are the driving factors for the adoption of digital learning in the Indian scenario?

Q2: Which drivers are more important for the successful adoption of digital learning in the Indian scenario?

So these research questions provide a motivation to analyse the drivers of digital learning in the Indian scenario and to identify the prominent drivers in implementing digital learning in the Indian scenario.

\section{Methodology}

In this section, the methodology selected for analysing drivers of digital learning has been presented, and the theoretical description of each step of methodology has also been described.

For analysing drivers of digital learning, a modelling approach has been considered. Interpretive structural modelling (ISM) approach has been used to analyse drivers of digital learning. ISM approach is based on the dependence between drivers. The reason for selecting the ISM approach in this study is, it provides a hierarchical relationship between factors by analysing factors and also help in identifying important driving factors. ISM has three terms, first is interpretive, which means it is based on a group of expert who decides whether factors influences other factors or not. Second is structural, which means, based on the interpretive expert decision, a structure is created among factors. The third is modelling in which a graphical model is developed based on the structure created and interpretative relationship.

The steps of ISM are as follows:

1. Identification of factors which are crucial for the considered problem

2. Establishing a contextual relationship between factors

3. Development of structural self-interaction matrix (SSIM) by comparing factors with each other and making a pairwise comparison matrix.

4. Development of initial reachability matrix (IRM) by converting contextual relationship of SSIM into binary number.

5. Development of final reachability matrix (IRM) by deploying transitivity rule in IRM. Here, the transitivity rule signifies that if a factor is affecting the second factor and that second factor is affecting the third factor, then indirectly the first factor affects the third factor.
6. Level partitioning of factors in which, for each factor, reachability set, antecedent set, and intersecting set are defined. The assignment of factors is based on the similarity between the reachability set and the intersection set. Wherever reachability set and intersection set are similar, level are assigned to that factor, and several iterations are performed till all factors got assigned a level. Here, in this step, reachability set for a particular factor signifies the driving set of that factor, and the antecedent set shows the dependent set of that factor. The intersection set includes common elements between the reachability set and the antecedent set.

7. Development of digraph based on levels of each factor. In this step, a simple graphical structure is created between factors by considering their levels and relationships.

8. Development of the ISM model using digraph. Here, in this step, the ISM model is derived by converting element nodes of a digraph with factors statement.

After including these eight steps of ISM, a structural model can be created, which depicts the interrelationship between factors and shows which factors are the most driving factors.

\section{Case Study}

In the current scenario, not only academia but also industries and other sectors are emerging digitally. In the manufacturing sector, Industry 4.0 concept is emerging recently and is gaining more importance. It enables the manufacturing sector to become digitally strong. Similarly, like manufacturing, other sectors are also adopting digital technologies.

The current scenario is profoundly affected by the COVID-19 pandemic. The adverse effect of the COVID-19 pandemic has changed the entire scenario. Some of the adverse effects are disruption in supply chain and restricted public gathering. To minimize the adverse effect of COVID-19, educational sectors are adopting digital learning to provide education to the students through digital media and also restricts public gathering.

The aim of this study is to analyse the drivers of digital learning in academia. From the literature review and in consultation with academia exerts, 16 drivers pertaining to digital learning have been identified. The identified drivers are presented in Fig. 1. 


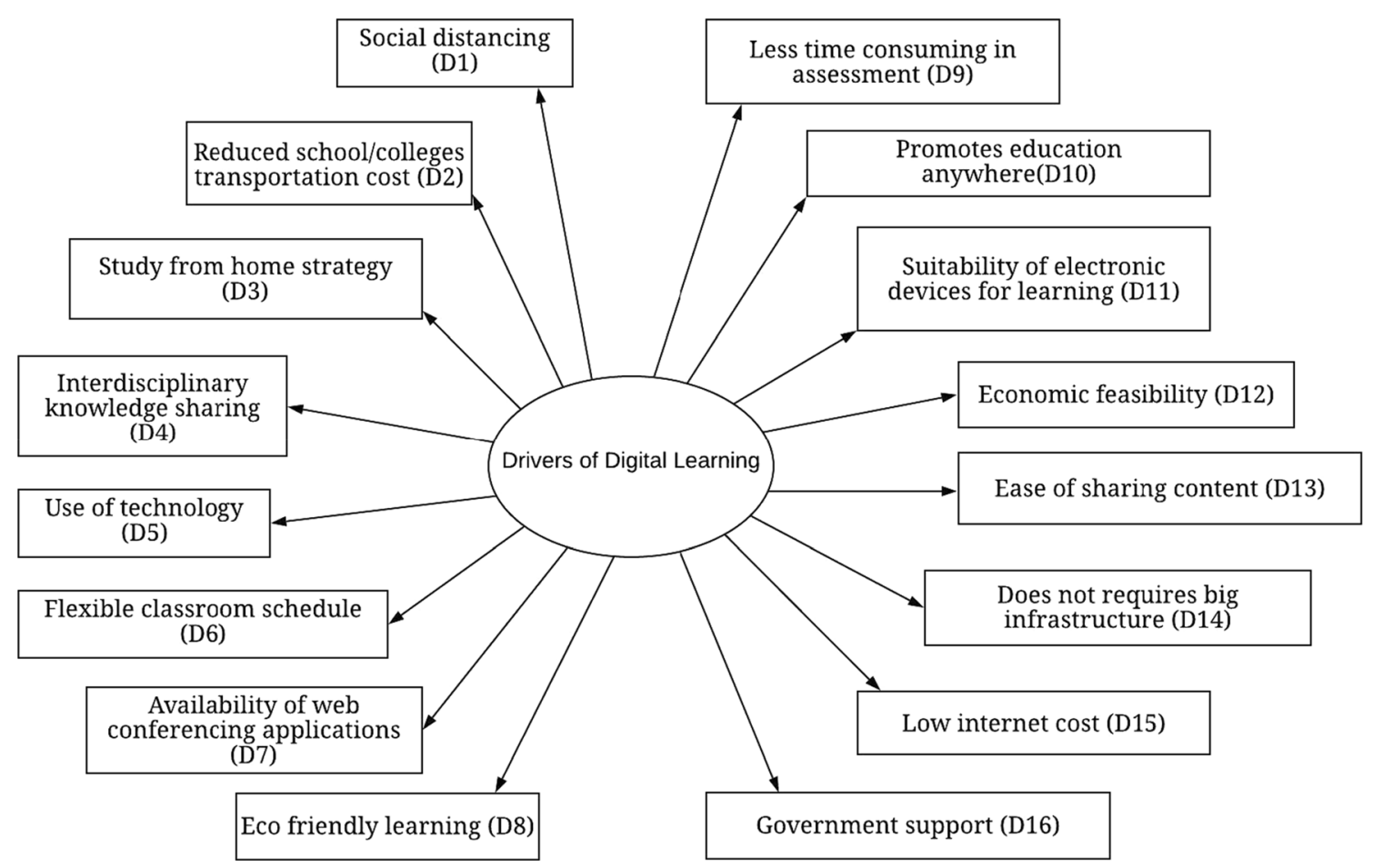

Fig. 1 Drivers of digital learning

\section{Promotes Social Distancing}

Digital classroom promotes physical distancing, which enables students to work in a safe environment by keeping themselves away with others. This strategy is very effective, especially during the COVID-19 pandemic.

\section{Reduced School/Colleges Transportation Cost}

Online classes reduce transportation cost for students as they can interact and study through online media without even going to school/colleges, which saves transportation cost.

\section{Promotes study from Home Strategy}

Study from home is convenient for students as well as teachers.

\section{Promotes Interdisciplinary Knowledge Sharing}

In the traditional classroom, students are bound to study specified subjects and may not get knowledge on interdisciplinary subjects. In an online classroom, apart from regular subjects, students can learn interdisciplinary subjects also.

\section{Promotes the Use of Technology}

Digital classroom promotes usage of technology in an efficient way.

\section{Supports Flexible Classroom Schedule}

Unlike a traditional classroom, the digital classroom can have a flexible schedule. Students can study and interact with faculties anytime based on mutual understanding with faculties. There are no time restrictions as in the traditional classroom.

\section{Availability of Web Conferencing Applications}

Availability of online conferencing applications like Cisco WebEx, Zoom, go to meeting, MS Team supports digital classroom. These applications are very effective in online classes and promote knowledge sharing in an efficient way.

\section{Eco-Friendly Learning}

Availability of eBooks, knowledge sharing through presentations, and assessment through online media makes paperless education to some extent. It creates an ecofriendly environment by reducing paper consumption and transportation. 


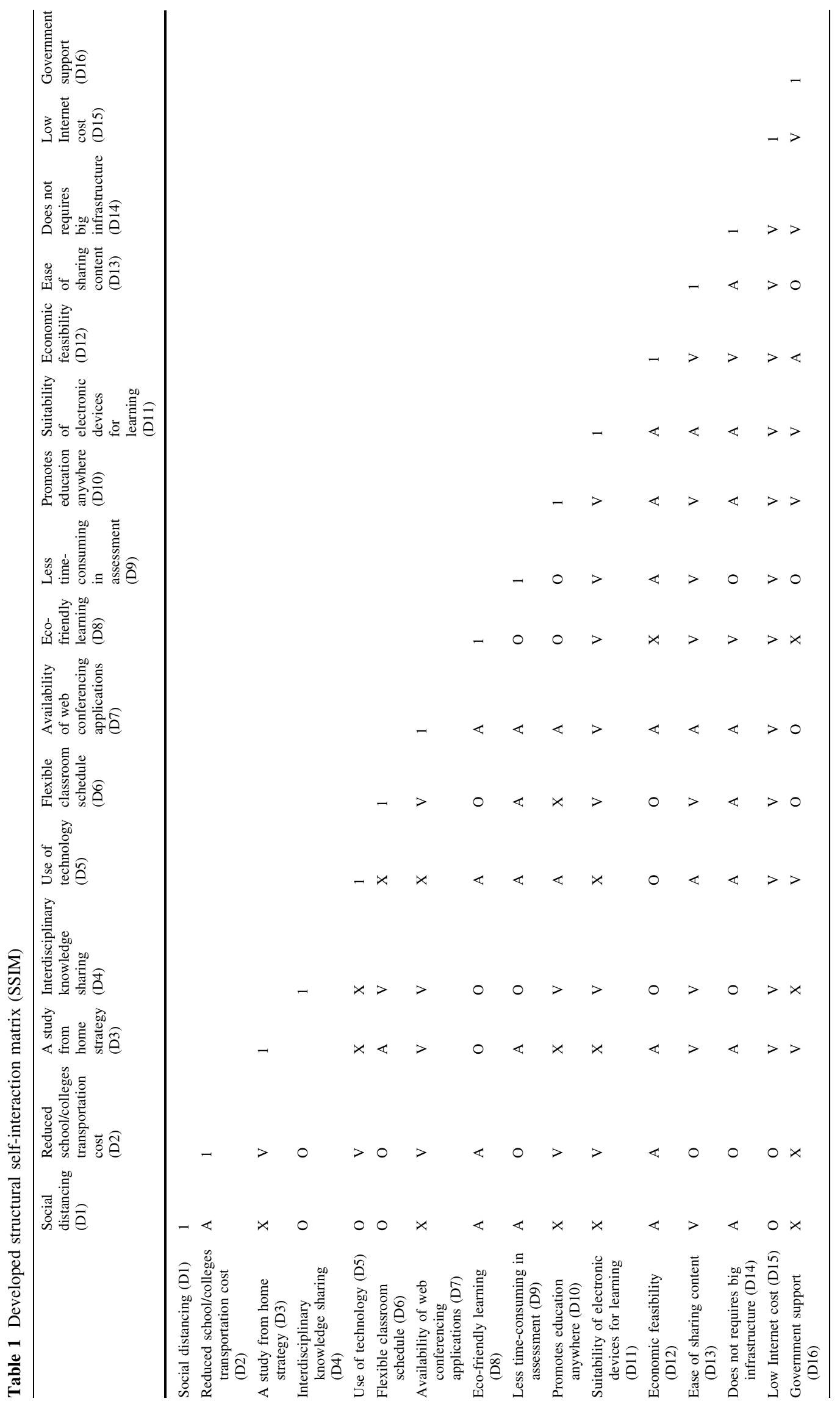


Table 2 Developed initial reachability matrix (IRM)

\begin{tabular}{llllllllllllllllll}
\hline & D1 & D2 & D3 & D4 & D5 & D6 & D7 & D8 & D9 & D10 & D11 & D12 & D13 & D14 & D15 & D16 \\
\hline D1 & 1 & 1 & 1 & 0 & 0 & 0 & 1 & 1 & 1 & 1 & 1 & 1 & 0 & 1 & 0 & 1 \\
D2 & 0 & 1 & 0 & 0 & 0 & 0 & 0 & 1 & 0 & 0 & 0 & 1 & 0 & 0 & 0 & 1 \\
D3 & 1 & 1 & 1 & 0 & 1 & 1 & 0 & 0 & 1 & 1 & 1 & 1 & 0 & 1 & 0 & 0 \\
D4 & 0 & 0 & 0 & 1 & 1 & 0 & 0 & 0 & 0 & 0 & 0 & 0 & 0 & 0 & 0 & 1 \\
D5 & 0 & 1 & 1 & 1 & 1 & 1 & 1 & 1 & 1 & 1 & 1 & 0 & 1 & 1 & 0 & 0 \\
D6 & 0 & 0 & 0 & 1 & 1 & 1 & 0 & 0 & 1 & 1 & 0 & 0 & 0 & 1 & 0 \\
D7 & 1 & 1 & 1 & 1 & 1 & 1 & 1 & 1 & 1 & 1 & 0 & 1 & 1 & 1 & 0 \\
D8 & 0 & 1 & 0 & 0 & 0 & 0 & 0 & 1 & 0 & 0 & 0 & 1 & 0 & 0 & 0 \\
D9 & 0 & 0 & 0 & 0 & 0 & 0 & 0 & 0 & 1 & 0 & 0 & 1 & 0 & 0 & 0 \\
D10 & 1 & 1 & 1 & 1 & 0 & 1 & 0 & 0 & 0 & 1 & 0 & 1 & 0 & 1 & 0 \\
D11 & 1 & 1 & 1 & 1 & 1 & 1 & 1 & 1 & 1 & 1 & 1 & 1 & 1 & 1 \\
D12 & 0 & 0 & 0 & 0 & 0 & 0 & 0 & 1 & 0 & 0 & 0 & 1 & 0 & 0 \\
D13 & 1 & 0 & 1 & 1 & 0 & 1 & 0 & 1 & 1 & 1 & 0 & 1 & 1 & 1 & 0 \\
D14 & 0 & 0 & 0 & 0 & 0 & 0 & 0 & 1 & 0 & 0 & 0 & 1 & 0 & 1 \\
D15 & 0 & 0 & 1 & 1 & 1 & 1 & 1 & 1 & 1 & 1 & 1 & 1 & 1 & 0 \\
D16 & 1 & 1 & 1 & 1 & 1 & 0 & 0 & 1 & 0 & 1 & 1 & 0 & 0 & 1 \\
\hline
\end{tabular}

Table 3 Developed Final reachability matrix (FRM)

\begin{tabular}{|c|c|c|c|c|c|c|c|c|c|c|c|c|c|c|c|c|}
\hline & D1 & D2 & D3 & D4 & D5 & D6 & D7 & D8 & D9 & D10 & D11 & D12 & D13 & D14 & D15 & D16 \\
\hline D1 & 1 & 1 & 1 & 0 & 0 & 0 & 1 & 1 & 1 & 1 & 1 & 1 & 0 & 1 & 0 & 1 \\
\hline D2 & 0 & 1 & 0 & 0 & 0 & 0 & 0 & 1 & 0 & 0 & 0 & 1 & 0 & 0 & 0 & 1 \\
\hline D3 & 1 & 1 & 1 & 0 & 1 & 1 & 0 & 0 & 1 & 1 & 1 & 1 & $1^{*}$ & 1 & 0 & 0 \\
\hline D4 & 0 & 0 & 0 & 1 & 1 & 0 & 0 & $1 *$ & 0 & 0 & 0 & 0 & 0 & 0 & 0 & 1 \\
\hline D5 & 0 & 1 & 1 & 1 & 1 & 1 & 1 & 1 & 1 & 1 & 1 & 0 & 1 & 1 & 0 & 0 \\
\hline D6 & 0 & 0 & 0 & 1 & 1 & 1 & 0 & 0 & 1 & 1 & 0 & 0 & 0 & 1 & 0 & 0 \\
\hline D7 & 1 & 1 & 1 & 1 & 1 & 1 & 1 & 1 & 1 & 1 & 0 & 1 & 1 & 1 & 0 & 0 \\
\hline D8 & 0 & $1^{*}$ & 0 & 0 & 0 & 0 & 0 & 1 & 0 & 0 & 0 & 1 & 0 & 0 & 0 & 1 \\
\hline D9 & 0 & 0 & 0 & 0 & 0 & 0 & 0 & $1 *$ & 1 & 0 & 0 & 1 & 0 & 0 & 0 & 0 \\
\hline D10 & 1 & 1 & 1 & 1 & 0 & 1 & 0 & 0 & 0 & 1 & 0 & 1 & 0 & 1 & 0 & 0 \\
\hline D11 & 1 & 1 & 1 & 1 & 1 & 1 & 1 & 1 & 1 & 1 & 1 & 1 & 1 & 1 & 0 & 0 \\
\hline D12 & 0 & 0 & 0 & 0 & 0 & 0 & 0 & 1 & 0 & 0 & 0 & 1 & 0 & 0 & 0 & 1 \\
\hline D13 & 1 & 0 & 1 & 1 & 0 & 1 & 0 & 1 & 1 & 1 & 0 & 1 & 1 & 1 & 0 & 0 \\
\hline D14 & 0 & 0 & 0 & 0 & 0 & 0 & 0 & 1 & 0 & 0 & 0 & 1 & 0 & 1 & 0 & 0 \\
\hline D15 & 0 & 0 & 1 & 1 & 1 & 1 & 1 & 1 & 1 & 1 & 1 & 1 & 1 & 1 & 1 & $1^{*}$ \\
\hline D16 & 1 & 1 & 1 & 1 & 1 & 0 & 0 & 1 & 0 & 1 & 1 & $1^{*}$ & 0 & 1 & 1 & 1 \\
\hline
\end{tabular}

* shows the transitive link

\section{Less Time-Consuming in Assessment}

Online assessment tools like google classroom and Ecoleaide, which are management systems to automate education in a digital way, consume less time in conducting an assessment of assignments, tutorials, and examinations. 

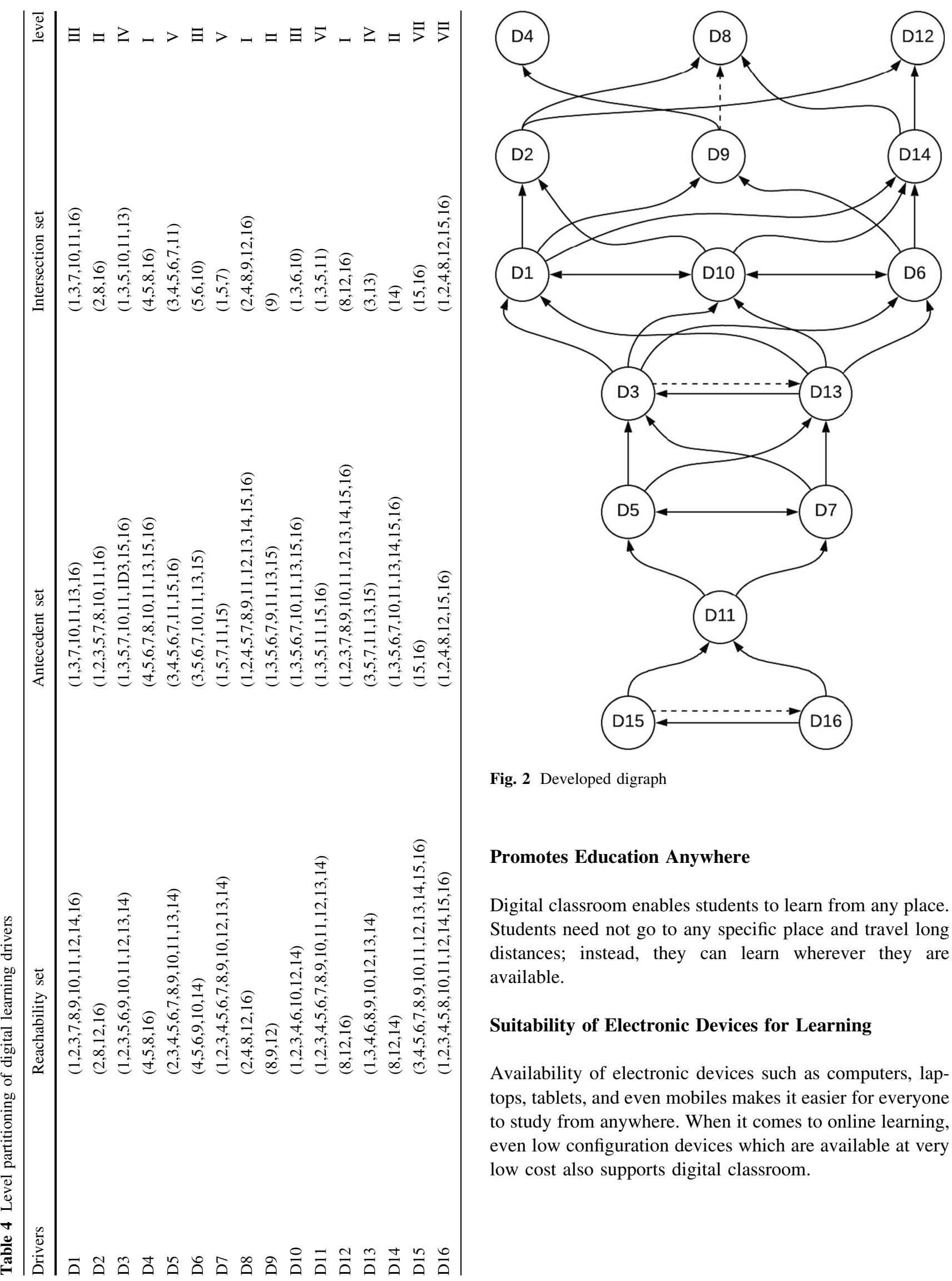

Fig. 2 Developed digraph

\section{Promotes Education Anywhere}

Digital classroom enables students to learn from any place. Students need not go to any specific place and travel long distances; instead, they can learn wherever they are available.

\section{Suitability of Electronic Devices for Learning}

Availability of electronic devices such as computers, laptops, tablets, and even mobiles makes it easier for everyone to study from anywhere. When it comes to online learning, even low configuration devices which are available at very low cost also supports digital classroom. 
Fig. 3 Developed interpretive structural model

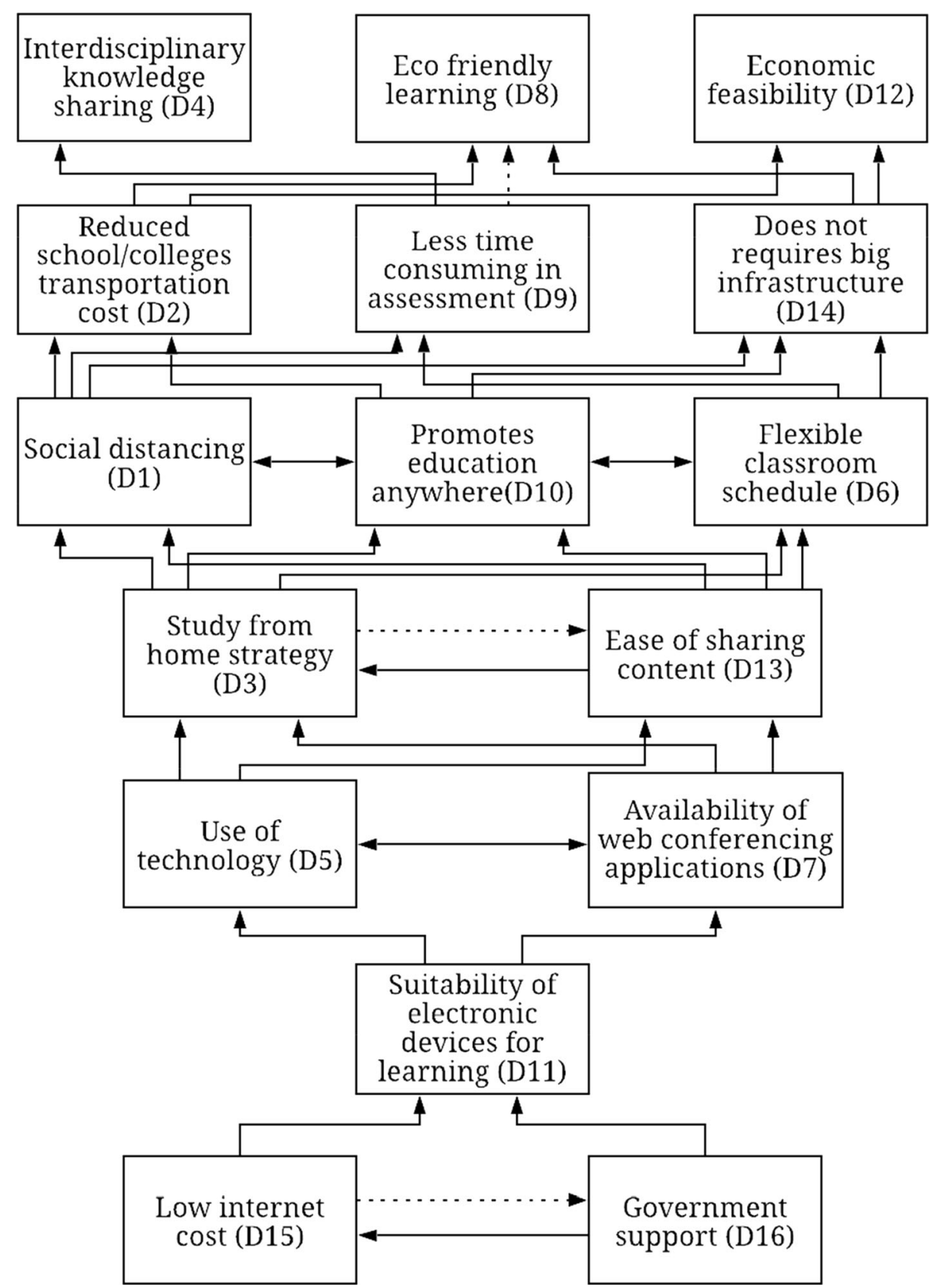

Does not Require Big Infrastructure

\section{Promotes Economic Feasibility}

Economy is the major consideration, especially in emerging countries. The availability of web conferencing applications, electronic devices, and Internet connectivity at low price supports economic feasibility.

\section{Ease of Sharing Content}

The most important aspect of a digital classroom is the ease of sharing content, notes, and study materials. Students can get study materials anywhere in no time.
Digital classroom enables a student to study from home and faculties to teach from home. Unlike the traditional classroom, it does not require any big infrastructure to accommodate all students.

\section{Low Internet Cost}

In developing countries like India, the cost of the Internet is very low. Low Internet cost is a great advantage while adopting digital learning. 
Fig. 4 Forbes report on mobile Internet cost [14]

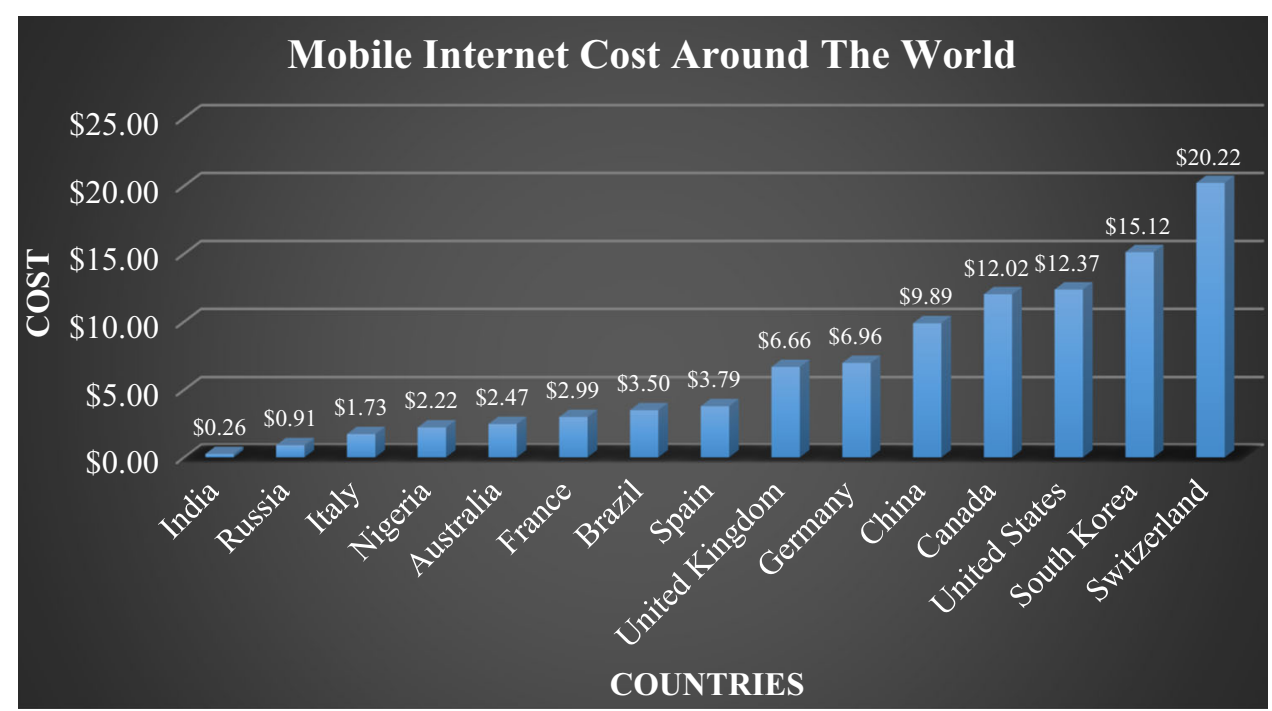

Table 5 Driving and dependence power of each driver

\begin{tabular}{lrc}
\hline Drivers & Driving power & Dependence power \\
\hline D1 & 11 & 7 \\
D2 & 4 & 9 \\
D3 & 11 & 9 \\
D4 & 4 & 9 \\
D5 & 12 & 8 \\
D6 & 6 & 8 \\
D7 & 13 & 5 \\
D8 & 4 & 13 \\
D9 & 3 & 9 \\
D10 & 8 & 10 \\
D11 & 14 & 6 \\
D12 & 3 & 13 \\
D13 & 10 & 6 \\
D14 & 3 & 11 \\
D15 & 14 & 2 \\
D16 & 12 & 7 \\
\hline
\end{tabular}

\section{Government Support}

In emerging economies, the government also supports digital learning. 'Digital India' moment by the Indian government encourages schools and colleges to adopt digital learning.

The identified 16 drivers have been analysed using the ISM approach. A structural model has been developed using the ISM approach for drivers. Inputs have been collected from academia experts. After collecting expert opinion, SSIM has been developed and is shown in Table 1. SSIM compares a driver with all other drivers. It shows how a driver is driving other drivers. For developing SSIM, four terms are used, namely 'V', 'A', 'X', and 'O'.

' $\mathrm{V}$ ' signifies factor is driving other factor, 'A' signifies factor is dependent on other factor, ' $\mathrm{X}$ ' signifies both factor drives each other, and ' $\mathrm{O}$ ' signifies both factor are independent. By using this rule, SSIM has been developed and is shown in Table 1.

After developing SSIM, IRM has been made by converting SSIM values to binary numbers. In IRM, value ' 1 ' signifies factor is driving other factor whereas ' 0 ' signifies factor is not driving other factor. IRM is shown in Table 2.

FRM has been made using IRM and by following transitivity rule. Transitivity rule signifies that if a factor is affecting the second factor and that second factor is affecting the third factor, then indirectly, the first factor affects the third factor. FRM is presented in Table 3.

After developing FRM, the next step is to compute for level partitioning. In level partitioning, three sets have been identified, namely reachability set, antecedent set, and intersection set. Reachability set for a factor includes all the factors which it drives. Antecedent set for a factor includes all the factors on which it depends. The intersection set for a factor includes all common factors between the intersection set and the antecedent set. The levelling of factors is done for factors whose reachability set and intersection set are similar. Several iterations are needed to get levels of all factors. The level partitioning of digital learning drivers is presented in Table 4. Iterations of level partition are shown in Appendix Table 6.

After getting levels of each driver, next step is to develop a digraph. Digraph is structural representation of drivers in their corresponding levels. The developed digraph is presented in Fig. 2. 
Fig. 5 MICMAC analysis

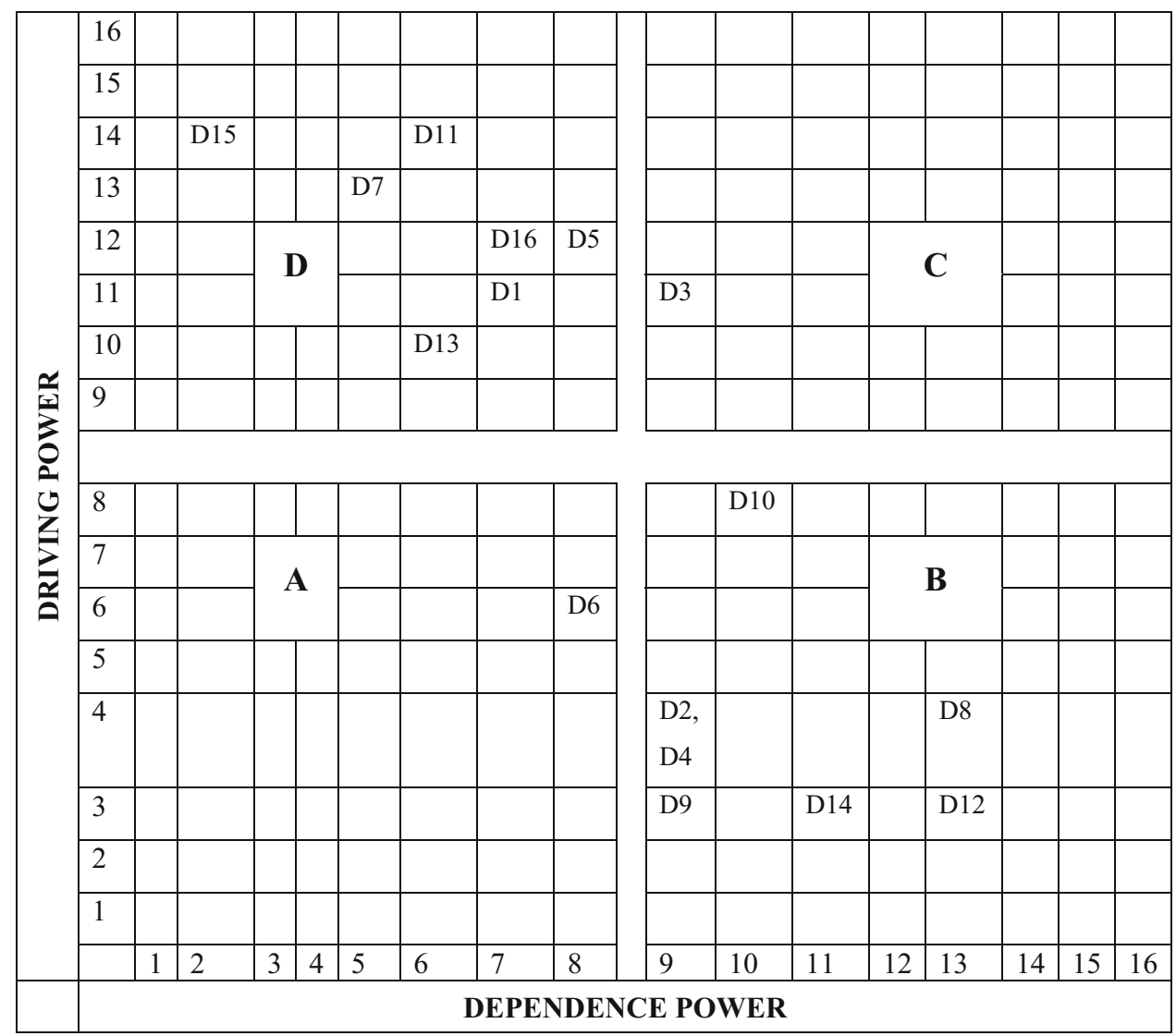

\section{Result}

In this section, analysed results of drivers and a structural model depicting key drivers have been presented. Sixteen drivers have been considered in this study, and steps of the ISM approach have been followed to develop an interpretive structural model. The developed ISM model is shown in Fig. 3.

From the developed ISM model, it can be seen that 'low Internet cost' and 'Government support' are the top driving factors that influence other factors. According to the Forbes survey in 2019, India's Internet cost is lowest compared with other countries, as shown in Fig. 4.

Low Internet cost is considered to be the most important driver for the adoption of digital learning in the Indian scenario. Low Internet cost is a great advantage while adopting digital learning. Low Internet cost supports educational institutions to adopt digital learning and also supports students to get knowledge anywhere and anyplace through digital learning.

Government support is an important driver for adopting digital learning. In developing countries such as India, the government is supporting digitalization for its growth and development. 'Digital India' movement is an example led by the Indian government towards digitalization.

\section{MICMAC Analysis}

MICMAC analysis shows the graphical representation of driving and dependence power of factors considered for study. MICMAC analysis is done to validate the ISM model. In MICMAC analysis, driving power and dependence power of each factor are calculated using FRM. The calculated driving and dependence power of each driver are presented in Table 5.

Further, MICMAC analysis categorizes drivers in four cluster namely autonomous cluster, dependent cluster, linkage cluster, and driving cluster and are represented as $\mathrm{A}, \mathrm{B}, \mathrm{C}$, and D respectively. MICMAC analysis is represented in Fig. 5. From MICMAC analysis, it is found that the most important driver of digital learning is 'low Internet cost (D15)' and 'Suitability of electronic devices for learning (D11)'.

The developed ISM model shows the dependency between the drivers and the MICMAC analysis validates the ISM model. The analysis of drivers and identification of top drivers of digital learning provides a motivation for the educational institutions to adopt digital learning. 


\section{Conclusions}

Digital Learning is one of the influential driver for skill development in the context of education. In order to attain the vision of national competitiveness, use of easily accessible technology, i.e. Internet for digital learning would be required which will replace traditional teaching and learning process. Despite the availability of digital media since its invention, its utilization was rare. The COVID-19 pandemic brought new challenge of teaching and learning process in front of the education system. To minimize the adverse effect of COVID-19, educational sectors are adopting digital learning to provide education to the students through digital media and also restricts public gathering. Thus, many students in India started accessing the digital media platforms for learning process. Reviewing the literatures showed that, even though the studies conducted to analyse the trend of digital learning in the form of survey analysis for its adoption level, there has been no comprehensive work related to driver analysis of digital learning. Thus, this study made an attempt to analyse the drivers pertaining to digital learning using ISM approach. Sixteen drivers pertaining to digital learning have been identified for analysis. The developed structural model was further validated using MICMAC analysis. The MICMAC analysis, i.e. driver and dependence analysis provided valuable understandings about the interdependencies between the digital learning drivers. The developed structural model revealed that 'Low Internet cost' and 'Government support' are the top driving factors which influence other factors. These two driving factors are considered to be the stepping stone in the adoption of digital learning process in COVID-19 and post-COVID-19. According to Forbes survey in 2019, the Internet cost in India is lowest when compared with other countries. Also, the Ministry of Human Resource Development of India have taken the initiatives for promoting digital learning by releasing the e-learning platforms. Having the influential drivers identified and understanding its importance, it is safe to conclude that the developed structural model would build the strong foundation of digital learning in Indian education schools and Universities. Moreover, the implementation of this model would create smooth learning environment in COVID-19 and motivates for innovation in post-COVID-19 scenario.

\section{Appendix}

See in Table 6

Table 6 Iterations of level partitioning of digital learning drivers

\begin{tabular}{|c|c|c|c|c|}
\hline Drivers & Reachability set & Antecedent set & Intersection set & level \\
\hline \multicolumn{5}{|c|}{ Iteration 1} \\
\hline D1 & $(1,2,3,7,8,9,10,11,12,14,16)$ & $(1,3,7,10,11,13,16)$ & $(1,3,7,10,11,16)$ & \\
\hline D2 & $(2,8,12,16)$ & $(1,2,3,5,7,8,10,11,16)$ & $(2,8,16)$ & \\
\hline D3 & $(1,2,3,5,6,9,10,11,12,13,14)$ & $(1,3,5,7,10,11,1 \mathrm{D} 3,15,16)$ & $(1,3,5,10,11,13)$ & \\
\hline D4 & $(4,5,8,16)$ & $(4,5,6,7,8,10,11,13,15,16)$ & $(4,5,8,16)$ & I \\
\hline D5 & $(2,3,4,5,6,7,8,9,10,11,13,14)$ & $(3,4,5,6,7,11,15,16)$ & $(3,4,5,6,7,11)$ & \\
\hline D6 & $(4,5,6,9,10,14)$ & $(3,5,6,7,10,11,13,15)$ & $(5,6,10)$ & \\
\hline D7 & $(1,2,3,4,5,6,7,8,9,10,12,13,14)$ & $(1,5,7,11,15)$ & $(1,5,7)$ & \\
\hline D8 & $(2,4,8,12,16)$ & $(1,2,4,5,7,8,9,11,12,13,14,15,16)$ & $(2,4,8,9,12,16)$ & I \\
\hline D9 & $(8,9,12)$ & $(1,3,5,6,7,9,11,13,15)$ & (9) & \\
\hline D10 & $(1,2,3,4,6,10,12,14)$ & $(1,3,5,6,7,10,11,13,15,16)$ & $(1,3,6,10)$ & \\
\hline D11 & $(1,2,3,4,5,6,7,8,9,10,11,12,13,14)$ & $(1,3,5,11,15,16)$ & $(1,3,5,11)$ & \\
\hline D12 & $(8,12,16)$ & $(1,2,3,7,8,9,10,11,12,13,14,15,16)$ & $(8,12,16)$ & I \\
\hline D13 & $(1,3,4,6,8,9,10,12,13,14)$ & $(3,5,7,11,13,15)$ & $(3,13)$ & \\
\hline D14 & $(8,12,14)$ & $(1,3,5,6,7,10,11,13,14,15,16)$ & $(14)$ & \\
\hline D15 & $(3,4,5,6,7,8,9,10,11,12,13,14,15,16)$ & $(15,16)$ & $(15,16)$ & \\
\hline D16 & $(1,2,3,4,5,8,10,11,12,14,15,16)$ & $(1,2,4,8,12,15,16)$ & $(1,2,4,8,12,15,16)$ & \\
\hline \multicolumn{5}{|c|}{ Iteration 2} \\
\hline D1 & $(1,2,3,7,9,10,11,14,16)$ & $(1,3,7,10,11,13,16)$ & $(1,3,7,10,11,16)$ & \\
\hline D2 & $(2,16)$ & $(1,2,3,5,7,10,11,16)$ & $(2,16)$ & II \\
\hline D3 & $(1,2,3,5,6,9,10,11,13,14)$ & $(1,3,5,7,10,11,13,15,16)$ & $(1,3,5,10,11,13)$ & \\
\hline D5 & $(2,3,5,6,7,9,10,11,13,14)$ & $(3,5,6,7,11,15,16)$ & $(3,5,6,7,11)$ & \\
\hline
\end{tabular}


Table 6 continued

\begin{tabular}{|c|c|c|c|c|}
\hline Drivers & Reachability set & Antecedent set & Intersection set & level \\
\hline D6 & $(5,6,9,10,14)$ & $(3,5,6,7,10,11,13,15)$ & $(5,6,10)$ & \\
\hline D7 & $(1,2,3,5,6,7,9,10,13,14)$ & $(1,5,7,11,15)$ & $(1,5,7)$ & \\
\hline D9 & (9) & $(1,3,5,6,7,9,11,13,15)$ & (9) & II \\
\hline D10 & $(1,2,3,6,10,14)$ & $(1,3,5,6,7,10,11,13,15,16)$ & $(1,3,6,10)$ & \\
\hline D11 & $(1,2,3,5,6,7,9,10,11,13,14)$ & $(1,3,5,11,15,16)$ & $(1,3,5,11)$ & \\
\hline D13 & $(1,3,6,9,10,13,14)$ & $(3,5,7,11,13,15)$ & $(3,13)$ & \\
\hline D14 & (14) & $(1,3,5,6,7,10,11,13,14,15,16)$ & (14) & II \\
\hline D15 & $(3,5,6,7,9,10,11,13,14,15,16)$ & $(15,16)$ & $(15,16)$ & \\
\hline D16 & $(1,2,3,5,10,11,14,15,16)$ & $(1,2,15,16)$ & $(1,2,15,16)$ & \\
\hline \multicolumn{5}{|c|}{ Driver 3} \\
\hline D1 & $(1,3,7,10,11,16)$ & $(1,3,7,10,11,13,16)$ & $(1,3,7,10,11,16)$ & III \\
\hline D3 & $(1,3,5,6,10,11,13)$ & $(1,3,5,7,10,11,13,15,16)$ & $(1,3,5,10,11,13)$ & \\
\hline D5 & $(3,5,6,7,10,11,13)$ & $(3,5,6,7,11,15,16)$ & $(3,5,6,7,11)$ & \\
\hline D6 & $(5,6,10)$ & $(3,5,6,7,10,11,13,15)$ & $(5,6,10)$ & III \\
\hline D7 & $(1,3,5,6,7,10,13)$ & $(1,5,7,11,15)$ & $(1,5,7)$ & \\
\hline D10 & $(1,3,6,10)$ & $(1,3,5,6,7,10,11,13,15,16)$ & $(1,3,6,10)$ & III \\
\hline D11 & $(1,3,5,6,7,10,11,13)$ & $(1,3,5,11,15,16)$ & $(1,3,5,11)$ & \\
\hline D13 & $(1,3,6,10,13)$ & $(3,5,7,11,13,15)$ & $(3,13)$ & \\
\hline D15 & $(3,5,6,7,10,11,13,15,16)$ & $(15,16)$ & $(15,16)$ & \\
\hline D16 & $(1,3,5,10,11,15,16)$ & $(1,15,16)$ & $(1,15,16)$ & \\
\hline \multicolumn{5}{|c|}{ Iteration 4} \\
\hline D3 & $(3,5,11,13)$ & $(3,5,7,11,13,15,16)$ & $(3,5,11,13)$ & IV \\
\hline D5 & $(3,5,7,11,13)$ & $(3,5,7,11,15,16)$ & $(3,5,7,11)$ & \\
\hline D7 & $(3,5,7,13)$ & $(5,7,11,15)$ & $(5,7)$ & \\
\hline D11 & $(3,5,7,11,13)$ & $(3,5,11,15,16)$ & $(3,5,11)$ & \\
\hline D13 & $(3,13)$ & $(3,5,7,11,13,15)$ & $(3,13)$ & IV \\
\hline D15 & $(3,5,7,11,13,15,16)$ & $(15,16)$ & $(15,16)$ & \\
\hline D16 & $(3,5,11,15,16)$ & $(15,16)$ & $(15,16)$ & \\
\hline \multicolumn{5}{|c|}{ Iteration 5} \\
\hline D5 & $(5,7,11)$ & $(5,7,11,15,16)$ & $(5,7,11)$ & $\mathrm{V}$ \\
\hline D7 & $(5,7)$ & $(5,7,11,15)$ & $(5,7)$ & $\mathrm{V}$ \\
\hline D11 & $(5,7,11)$ & $(5,11,15,16)$ & $(5,11)$ & \\
\hline D15 & $(5,7,11,15,16)$ & $(15,16)$ & $(15,16)$ & \\
\hline D16 & $(5,11,15,16)$ & $(15,16)$ & $(15,16)$ & \\
\hline \multicolumn{5}{|c|}{ Iteration 6} \\
\hline D11 & (11) & $(11,15,16)$ & (11) & VI \\
\hline D15 & $(11,15,16)$ & $(15,16)$ & $(15,16)$ & \\
\hline D16 & $(11,15,16)$ & $(15,16)$ & $(15,16)$ & \\
\hline \multicolumn{5}{|c|}{ Iteration 7} \\
\hline 15 & $(15,16)$ & $(15,16)$ & $(15,16)$ & VII \\
\hline 16 & $(15,16)$ & $(15,16)$ & $(15,16)$ & VII \\
\hline
\end{tabular}

\section{References}

1. M.J. Sousa, Á. Rocha, Digital learning: developing skills for digital transformation of organizations. Future Gener. Comput. Syst. 91, 327-334 (2019)
2. M.H. Lin, H.G. Chen, A study of the effects of digital learning on learning motivation and learning outcome. Eurasia J. Math. Sci. Technol. Educ. 13(7), 3553-3564 (2017)

3. M. Warschauer, The paradoxical future of digital learning. Learn. Inq. 1(1), 41-49 (2007)

4. C. Lewis, Driving factors for e-learning: an organisational perspective. Perspect. Policy Pract. High. Educat. 6(2), 50-54 (2002) 
5. Y. Liu, H. Li, C. Carlsson, Factors driving the adoption of m-learning: an empirical study. Comput. Educ. 55(3), 1211-1219 (2010)

6. Y. Liu, S. Han, H. Li, Understanding the factors driving m-learning adoption: a literature review. Campus-Wide Inf. Syst. 27(4), 210-226 (2010)

7. H. Estelami, An exploratory study of the drivers of student satisfaction and learning experience in hybrid-online and purely online marketing courses. Mark. Educ. Rev. 22(2), 143-156 (2012)

8. T. Teo, S.L. Wong, Modeling key drivers of e-learning satisfaction among student teachers. J. Educ. Comput. Res. 48(1), 71-95 (2013)

9. E. Medland, Assessment in higher education: drivers, barriers and directions for change in the UK. Assess. Eval. High. Educ. 41(1), 81-96 (2016)

10. W.W. Porter, C.R. Graham, R.G. Bodily, D.S. Sandberg, A qualitative analysis of institutional drivers and barriers to blended learning adoption in higher education. Internet High. Educ. 28, 17-27 (2016)
11. W.W. Porter, C.R. Graham, Institutional drivers and barriers to faculty adoption of blended learning in higher education. Br. J. Edu. Technol. 47(4), 748-762 (2016)

12. M. Sarrab, I. Al Shibli, N. Badursha, An empirical study of factors driving the adoption of mobile learning in Omani higher education. Int. Rev. Res. Open Distrib. Learn. 17(4), 331-349 (2016)

13. C. Shao, An empirical study on the identification of driving factors of satisfaction with online learning based on TAM. In 5th international conference on economics, management, law, and education (EMLE 2019), Atlantis Press, 1067-1073 January 2020

14. N. McCarthy, The cost of mobile internet around the world [Infographic].

Forbes

(2019) https://www.forbes.com/sites/niallmccarthy/2019/03/05/the-costof-mobile-internet-around-the-world-infographic/\#2fd38561226e Assessed 04 Aug 2020

Publisher's Note Springer Nature remains neutral with regard to jurisdictional claims in published maps and institutional affiliations. 